\title{
Estudo relacionado ao Zika Vírus e a Microcefalia: evidências científicas
}

\author{
Study related to Zika Virus and Microcephaly: scientific evidence
}

\section{Estudio relacionado con el Virus del Zika y la Microcefalia: evidencia científica}

Luana Eugênia Silva de Novaes ${ }^{1 *}$, Kamilly Cristine de Queiroz Pinho ${ }^{1}$, Carla Cristina Costa Lima ${ }^{1}$, Margareth Maria Braun Guimarães Imbiriba ${ }^{1}$, Rita do Socorro Ribeiro Quaresma Oliveira ${ }^{1}$, Tamires de Nazaré Soares ${ }^{1}$, Maria Myrle Braun Guimarães ${ }^{1}$, Mariane Cardoso Bittencourt ${ }^{1}$, Glenda Klicia Silva Rodrigues ${ }^{1}$, Karolayne Teles Costa ${ }^{1}$.

\section{RESUMO}

Objetivo: Descrever as evidências cientificas sobre a prevalência do Zika vírus no Brasil, conforme as publicações científicas no período de 2015 a 2017. Metodologia: O estudo descritivo com abordagem qualitativa do tipo revisão da literatura. Essa pesquisa faz uma análise minuciosa através de uma revisão sistemática de artigos publicados no período de 2015 a 2017. Para a identificação das fontes utilizaram-se os seguintes catálogos de indexação: Biblioteca do Centro Latino Americano e do Caribe de Informação em Ciências da Saúde (BIREME), Scientific Eletronic Library Online (SciELO) e Biblioteca Virtual em Saúde Enfermagem (BVS), além de dados coletados nos órgãos de saúde mundial, federal e estadual. A pesquisa baseia-se na busca pelas palavras chaves "Zika vírus" e "Microcefalia". Discussão: Após a análise dos artigos, foram destacados alguns pontos como epidemia, diagnóstico, consequência para o feto, prevenção e equipe multiprofissional. Considerações finais: Os dados analisados, permitiu constatar que investir em educação em saúde, incentivo ao pré-natal, diagnóstico, prevenção e saneamento básico são fundamentais para o controle do vetor, sendo a atuação do enfermeiro (a) nos três níveis de atenção (primária, secundária e terciária) essencial, para que no futuro as gerações não sofram com o vírus e suas consequências.

Palavras-chave: Microcefalia, Zika, Prevalência.

\begin{abstract}
Objective: To describe the scientific evidence on the prevalence of Zika virus in Brazil, according to scientific publications in the period 2015 to 2017. Methodology: The descriptive study with a qualitative approach of the literature review type. This research makes a thorough analysis through a systematic review of articles published in the period 2015 to 2017 . To identify the sources, the following indexation catalogs were used: library of the Latin American and Caribbean Center for Information on Health Sciences (BIREME), Scientific Eletronic Library Online (SciELO) and Virtual Health Library- Nursing (VHL), in addition to data collected in the global, federal and state health organs. The search is based on the search for the key words "Zika virus" and "microcephaly". Discussion: After the analysis of the articles, some points were highlighted as epidemic, diagnosis, consequence to the fetus, prevention and multidisciplinary team. Final Considerations: The data analyzed, allowed us to verify that investing in health education, encouraging prenatal care, diagnosis, prevention and basic sanitation are fundamental for vector control, and the nurse's performance (a) is in the three levels of care (primary, essential, so that in the future generations do not suffer from the virus and its consequences.
\end{abstract}

Keywords: Microcephaly, Zika, Prevalence.

\section{RESUMEN}

Objetivo: Describir la evidencia científica sobre la prevalencia del virus del Zika en Brasil, según publicaciones científicas en el período 2015-2017. Metodología: El estudio descriptivo con un enfoque cualitativo del tipo de revisión de la literatura. Esta investigación realiza un análisis exhaustivo a través de una revisión sistemática de los artículos publicados en el período 2015-2017. Para identificar las fuentes, se utilizaron los siguientes catálogos de indexación: biblioteca del Centro Latinoamericano y del Caribe de Información sobre

1 Universidade da Amazônia (UNAMA), Belém-Pará. *E-mail: luna_novaes@hotmail.com 
Ciencias de la Salud (BIREME), Biblioteca Científica Eletronic Online (SciELO) y Biblioteca Virtual de SaludEnfermería (VHL), además de los datos recogidos en los órganos sanitarios globales, federales y estatales. La búsqueda se basa en la búsqueda de las palabras clave "Virus de Zika" y "microcefalia". Discusión: Después del análisis de los artículos, algunos puntos fueron destacados como epidemia, diagnóstico, consecuencia para el feto, prevención y equipo multidisciplinario. Consideraciones Finales: Se concluir que invertir en educación sanitaria y saneamiento basic son fundamentales para el control del vector, guiando a la población a ser extremadamente importante con las medidas adoptadas por el Ministerio de Salud, pero la prioridad es el (a) (enfermera a) en los tres niveles de atención, además de intensificación.

Palabras clave: Microcefalia, Zika, Prevalencia.

\section{INTRODUÇÃO}

O objeto de estudo é a Microcefalia causada pelo Zika Vírus. O vírus Zika é um microrganismo envelopado de cadeia de RNA simples (não segmentado), da família flaviviridae e gênero flavivirus, transmitido pelo mosquito Aedes Aegypti. Inicialmente, esse vírus foi identificado na Uganda, em macacos Rhesus, na Floresta Zika por isso denominado com esse nome, posteriormente, foi identificado em seres humanos, em 1952 (VASCONCELOS PFC, 2015).

O vírus Zika ocasiona diversos sintomas, principalmente a febre, que geralmente é acompanhada por cefaleia, mal-estar, edema, erupção cutânea, geralmente maculopapular e dores articulares. Nos quadros mais severos o sistema nervoso central (SNC) pode ser acometido, provocando a síndrome de Guillain-Barré, meningite e mielite transversa, que é frequentemente registrado na Polinésia Francesa e no Brasil, demostrando o pouco conhecimento sobre a doença (VASCONCELOS PFC, 2015).

O que impulsionou a realização deste trabalho foi o aumento alarmante dos casos de microcefalia relacionados ao Zika vírus em bebês recém-nascidos, onde a enfermagem tem como papel principal acompanhar e orientar o pré-natal de gestantes, assim contribuindo para um diagnóstico precoce de doenças e ações preventivas como exames, vacinas e classificação de doenças exantemáticas em gestante. Isso nos serve para promover um cuidado adequado para a saúde da mãe e do recém-nascido (RN) com microcefalia (REIS RP,2015).

De acordo com Castro R, (2016), em pesquisas realizadas no ano de 2016, foi constatada a relação entre o Zika Vírus e a Microcefalia, comprovado pelo laboratório da Fiocruz, essa afirmação se dá pelos achados em 32 bebes com microcefalia, onde 13 foram diagnosticados a infecção pelo vírus (soro e/ou liquido cefalorraquidiano) e em nenhum desses bebes foi localizado outro tipo de doença que podem ocasionar as malformações congênitas.

Até o momento, a microcefalia é a única complicação perinatal associada ao vírus Zika, além de possíveis alterações oculares, como hipoplasia do nervo ótico, miopia e hipermetropia e alterações fundoscópicas (SALGE AKM, et al., 2016). Diante desta problemática, surgiram os seguintes questionamentos: Quais as evidências cientificas sobre a situação epidemiológica do vírus Zika, conforme publicações cientificas no período de 2015 a 2017 e o que a literatura aponta sobre a prevalência do vírus Zika?

Desta forma, o principal objetivo deste estudo é revisar e analisar as evidências cientificas sobre a prevalência do Zika vírus no Brasil, conforme as publicações cientificas no período de 2015 a 2017 e como objetivos específicos realizaremos o levantamento das produções cientificas desenvolvidas acerca do tema, sintetizando os tipos de pesquisa por abordagem metodológica e principais resultados obtidos e identificando as contribuições da enfermagem para a produção cientifica acerca do tema.

\section{MÉTODOS}

O estudo foi descritivo com abordagem qualitativa do tipo revisão da literatura. Essa pesquisa faz uma análise minuciosa do objeto de estudo, através de artigos publicados no período de 2015 a 2017, seguindo as etapas de identificação de fontes, localização, compilação e fichamento. 
Para a identificação das fontes utilizaram-se os seguintes catálogos de indexação: Biblioteca do Centro Latino Americano e do Caribe de Informação em Ciências da Saúde (BIREME), Scientific Eletronic Library Online (SciELO) e Biblioteca Virtual em Saúde - Enfermagem (BVS). A pesquisa se baseou na busca pelas palavras chaves "Zika vírus", "Microcefalia" e "Prevalência", de forma a concentrar-se na ocorrência de casos de Zika Vírus em gestantes correlatos a microcefalias em recém-nascidos.

Para a escolha dos artigos empregou-se critério de inclusão, sendo eles: artigos publicados em português, artigos completos, disponíveis nos bancos de dados, disponíveis gratuitamente. Assim, como critério de exclusão, consideramos os artigos que não se referem a microcefalia adquirida por Zika vírus, artigos que não possuem referência, textos incompletos ou repetidos, textos em inglês, espanhol, artigos de revisões da literatura, que não obedecem ao critério de casos identificados no período de 2015 a 2017.

Na presente revisão foram realizadas inserções de palavras relativas ao contexto do tema investigado que foram Zika Vírus e Microcefalia. A busca foi realizada pelo acesso on-line nos bancos de dados: Scielo, Bireme e BVS utilizando os tópicos mencionados, evidenciamos 362 referências bibliográficas, que foram submetidas aos critérios de exclusão por não atenderem os critérios propostos: Não apresentavam resumos, Não se referia a Zika vírus relacionado a Microcefalia adquirida, Incompletos e repetidos nas bases de dados, em língua estrangeira e publicação fora do período estipulado de 2015 a 2017.

Após esta exclusão inicial resultou em 188 publicações remanescentes, realizamos a leitura dos resumos disponíveis avaliando os artigos que contemplavam os critérios. Dessa forma foram eleitos dez (10) artigos que compuseram o banco de dados para análise e discussão, pois respondem às questões diretamente da pesquisa.

\section{RESULTADOS E DISCUSSÕES}

Pode-se observar a mensuração dos artigos encontrados nos bancos de dados, que foram analisados utilizando a inserção de palavras sobre o tema Zika vírus e Microcefalia, através de acesso on-line, empregando tópicos mencionados nos critérios de inclusão (Gráfico 1).

Gráfico 1 - Distribuição de artigos encontrados em cada bases de dados.

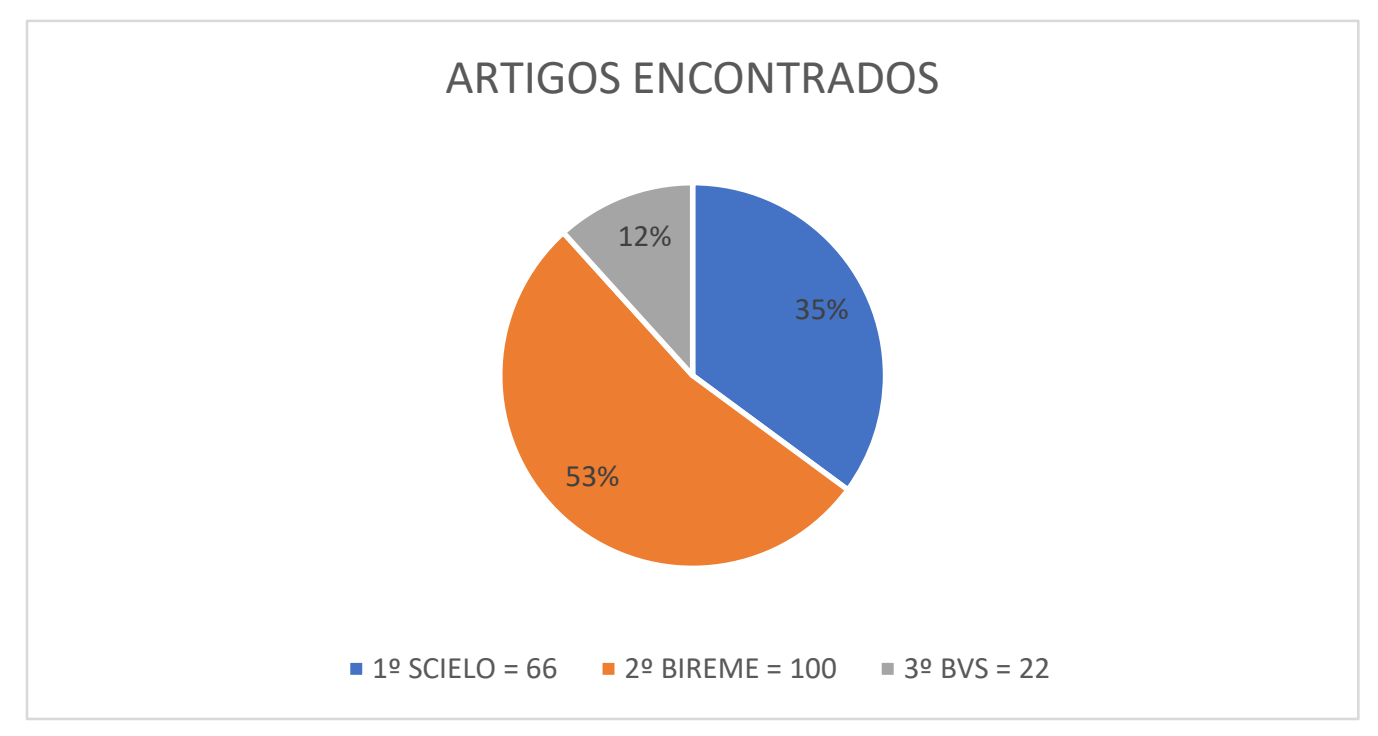

Fonte: Novaes LG, 2018.

Os artigos selecionados foram caracterizados os que compuseram o banco de dados para análise e discussão, pois respondem às questões diretamente da pesquisa, sendo, eles organizados na tabela a seguir (Tabela 1). 
Tabela 1 - Caracterização dos artigos de acordo com base de dados, ano de publicação, tipo/abordagem título e autores.

\begin{tabular}{|c|c|c|c|c|c|}
\hline $\mathbf{N}^{\circ}$ & $\begin{array}{l}\text { Base de } \\
\text { dados }\end{array}$ & Ano & $\begin{array}{c}\text { Tipo/ } \\
\text { Abortagem }\end{array}$ & Título & Autores \\
\hline 1 & Scielo & 2017 & Descritiva & $\begin{array}{l}\text { Perfil da demanda e dos benefícios } \\
\text { de prestação continuada } \\
\text { concedidos a crianças } \\
\text { diagnóstico de com } \\
\text { Brasil. }\end{array}$ & $\begin{array}{l}\text { Pereira EL, et al. } \\
\quad(2017)\end{array}$ \\
\hline 2 & Scielo & 2017 & Descritiva & $\begin{array}{l}\text { Descrição clínico-epidemiológica } \\
\text { dos nascidos vivos com microcefalia } \\
\text { no estado de Sergipe, } 2015 \text {. }\end{array}$ & $\begin{array}{l}\text { Cabral CM, et al. } \\
\qquad(2017)\end{array}$ \\
\hline 3 & Scielo & 2017 & Descritiva & $\begin{array}{l}\text { Vírus Zika: emergência de um velho } \\
\text { conhecido. }\end{array}$ & $\begin{array}{c}\text { Brogueira } \mathrm{P} \text {, et al. } \\
(2017)\end{array}$ \\
\hline 4 & Scielo & 2016 & Qualitativa & $\begin{array}{l}\text { Microcefalia e outras manifestações } \\
\text { relacionadas ao vírus Zika: impacto } \\
\text { nas crianças, nas famílias e nas } \\
\text { equipes de saúde. }\end{array}$ & $\begin{array}{l}\text { Brunoni D, et al. } \\
\qquad(2016)\end{array}$ \\
\hline 5 & Scielo & 2016 & Descritiva & $\begin{array}{l}\text { Características dos primeiros casos } \\
\text { de microcefalia possivelmente } \\
\text { relacionados ao vírus Zika } \\
\text { notificados na região metropolitana } \\
\text { de Recife, Pernambuco. }\end{array}$ & $\begin{array}{l}\text { Vargas } A \text {, et al. } \\
\qquad(2016)\end{array}$ \\
\hline 6 & Scielo & 2016 & Descritiva & Microcefalia e vírus Zika. & $\begin{array}{l}\text { Vasconcelos PFC, } \\
\text { et al. (2016) }\end{array}$ \\
\hline 7 & Bireme & 2015 & Qualitativa & Surto de microcefalia no Brasil. & Reis RP (2015) \\
\hline 8 & Bireme & 2016 & Descritiva & $\begin{array}{l}\text { Síndrome da infecção congênita } \\
\text { pelo vírus Zika. }\end{array}$ & $\begin{array}{c}\text { Eickmann SH, et al. } \\
(2016)\end{array}$ \\
\hline 9 & Bireme & 2016 & Discritiva & $\begin{array}{l}\text { Microcefalia no Brasil: prevalência e } \\
\text { caracterização dos casos a partir do } \\
\text { sistema de informações sobre } \\
\text { nascidos vivos (sinasc), 2000-2015 }\end{array}$ & $\begin{array}{l}\text { Marinho F, et al. } \\
\qquad(2016)\end{array}$ \\
\hline 10 & Bireme & 2017 & Qualitativa & $\begin{array}{l}\text { Produção de sentidos parentais no } \\
\text { cuidado de crianças com } \\
\text { microcefalia por vírus Zika. }\end{array}$ & Sá FE, et al. (2017) \\
\hline
\end{tabular}

Fonte: Dados da pesquisa, 2015 a 2017.

Após a seleção dos artigos, que enfatizam a temática Zika vírus e a Microcefalia, os dados foram analisados e separados de acordo com seus objetivos e seus principais resultados, como o número de casos de microcefalia no Brasil, a relação de microcefalia com o Zika vírus e o plano de apoio ao paciente e sua família (Tabela 2). 
Tabela 2 - Síntese dos estudos selecionados de acordo com o objetivo e principais resultados do estudo.

\begin{tabular}{|c|c|c|}
\hline $\mathbf{N}^{\circ}$ & Objetivo & Resultados \\
\hline 1 & $\begin{array}{l}\text { Apresentar dados da demanda e da concessão do } \\
\text { Benefício de Prestação Continuada (BPC) para } \\
\text { crianças com microcefalia no território nacional } \\
\text { desde } 2009 \text {. }\end{array}$ & $\begin{array}{l}\text { O Ministério da Saúde divulgou que de } 01 / 01 / 2015 \text { a } 31 / 12 / 2016 \text { foram notificados } 10.867 \text { casos } \\
\text { de microcefalia segundo os parâmetros do Protocolo de Vigilância, dos quais } 3.183 \text { casos } \\
(29,3 \%) \text { permaneciam em investigação. Dos } 7.684 \text { casos que foram investigados e classificados, } \\
2.366 \text { foram confirmados, } 49 \text { classificados como prováveis e } 5.269 \text { descartados. Ainda } \\
\text { permanecem em investigação } 3.183 \text { casos. }\end{array}$ \\
\hline 2 & $\begin{array}{l}\text { Descrever as características clínicas e } \\
\text { epidemiológicas dos casos de microcefalia em } \\
\text { nascidos vivos no estado de Sergipe, Brasil, e } \\
\text { calcular as prevalências em seus municípios. }\end{array}$ & $\begin{array}{l}\text { Confirmaram-se } 83 \text { casos de microcefalia, com três óbitos; a prevalência nos } 26 \text { municípios com } \\
\text { casos confirmados variou de } 18 \text { a } 185 / 10.000 \text { nascidos vivos; a mediana do perímetro cefálico } \\
\text { foi de } 31 \mathrm{~cm} \text { (amplitude: } 22,5 \text { a } 33,0 \mathrm{~cm} \text { ); na ultrassonografia transfontanelar, observou-se } \\
\text { agenesia de corpo caloso (26/43), lisencefalia (12/43), ausência de linha média (10/43) e } \\
\text { ventriculomegalia (8/43); } 40 \text { mães referiram exantema na gestação, } 23 \text { no primeiro trimestre, } \\
\text { com prurido, artralgia e cefaleia; sete foram positivas para infecções potencialmente causadoras } \\
\text { de malformações. }\end{array}$ \\
\hline 3 & $\begin{array}{l}\text { Descrever a relação do vírus Zika com a } \\
\text { microcefalia e outras malformações congênitas. }\end{array}$ & $\begin{array}{l}\text { Em mulheres grávidas, sempre que haja história de possível exposição ao vírus Zika, esta deve } \\
\text { ser testada para a ocorrência de infecção devido ao grande número de complicações } \\
\text { relacionadas a doença (Meningite, encefalite e síndrome de Guillain-Barré). Grávidas cuja } \\
\text { exposição tenha ocorrido há mais de } 12 \text { semanas, deverão realizar teste sorológico com } \\
\text { pesquisa de anticorpos lgM específicos, e por imunohistoquímica no cordão umbilical e placenta, } \\
\text { confirmando infecção congênita. }\end{array}$ \\
\hline 4 & $\begin{array}{l}\text { Apresentar um panorama nacional e internacional } \\
\text { atual dos estudos sobre o vírus Zika (ZIKV) e, } \\
\text { ancorado no avanço deste conhecimento, refletir } \\
\text { sobre planos de ação voltados para as crianças, } \\
\text { famílias e equipes de saúde envolvidas. }\end{array}$ & $\begin{array}{l}\text { O suporte sócio emocional auxilia no enfrentamento das dificuldades que pais de crianças com } \\
\text { déficit intelectual passam. Além do acompanhamento da criança, faz-se necessária a atenção } \\
\text { aos pais para verificar problemas emocionais e de qualidade de vida. A comunidade científica e } \\
\text { os serviços de saúde devem fazer esse acompanhamento, para que haja uma maior } \\
\text { resolutividade nos problemas relatados pelas famílias, assegurando ao pais e familiares que irão } \\
\text { conduzir a criança para os serviços especializados todo apoio de uma equipe multidisciplinar. }\end{array}$ \\
\hline 5 & $\begin{array}{l}\text { Descrever os primeiros casos de microcefalia } \\
\text { possivelmente relacionados ao vírus Zika em } \\
\text { nascidos vivos notificados na Região Metropolitana } \\
\text { do Recife, Pernambuco, Brasil. }\end{array}$ & $\begin{array}{l}\text { Foram confirmados } 40 \text { casos com microcefalia, distribuídos em oito municípios da Região } \\
\text { Metropolitana do Recife, com maior concentração no Recife }(\mathrm{n}=12) \text {; a mediana do perímetro } \\
\text { cefálico foi de } 29 \mathrm{~cm} \text {, do perímetro torácico, } 31 \mathrm{~cm} \text {, e do peso, } 2.628 \text { gramas; } 21 / 25 \text { casos } \\
\text { apresentaram calcificação cerebral, ventriculomegalia ou lisencefalia; entre as } 40 \text { mães, } 27 \\
\text { referiram exantema na gestação, } 20 \text { no primeiro trimestre e sete no segundo, além de prurido, } \\
\text { cefaleia, mialgia e ausência de febre. }\end{array}$ \\
\hline
\end{tabular}

REAS/EJCH | Vol.Sup.n.38 | e1705 | DOI: https://doi.org/10.25248/reas.e1705.2020 Página 5 de 9 
Há uma clara necessidade de fortalecimento das ações antivetoriais, que é a única medida concreta que hoje temos para diminuir os casos de infecções pelo ZIKV. É urgente que ações concretas sejam feitas em todos os níveis públicos e com o envolvimento da sociedade para reduzir os índices de infestação vetorial, pois ao se reduzir a quantidade de vetores se reduzirão as taxas de incidência e obviamente os casos de microcefalia e outras malformações congênitas.

Buscarmos novas estratégias para combater o vetor, Aedes aegypti, principal transmissor das epidemias que assolam o nosso país. As formas de combate ao mosquito incluem o controle Mensurar a epidemia por microcefalia relacionado ao Zika químico, bastante empregado no Brasil, vários desses produtos são tóxicos ao homem, e podem desenvolver resistência nos vetores. O controle ambiental cria condições adversas ao desenvolvimento de vetores, além de ser uma medida com efeito de longo prazo, traz muitos outros benefícios a saúde, ao conforto da população e a atividade econômica.

Descrever sobre a nova síndrome da infecção congênita pelo vírus Zika

Ao exame físico dos recém-nascidos com síndrome da infecção congênita pelo ZIKV, chama atenção a microcefalia, geralmente grave, com importante desproporção craniofacial. Outras dismorfias, como acentuada protuberância óssea occipital, fontanelas fechadas ao nascer, excesso de pele e/ou dobras de pele no escalpo, além de hérnia umbilical são frequentemente observadas.

Descrever os coeficientes de prevalência caracterizar os casos de microcefalia ao nascer no Brasil, no período 2000-2015.

A média anual de casos de microcefalia foi 164 no período 2000-2014, enquanto em 2015 foram registrados 1.608 casos $(54,6$ casos por 100 mil NV). Coeficientes mais elevados foram observados entre prematuros $\left(81,7 ; \mathrm{IC}_{95 \%}\right.$ 72,3; 92,2), nascidos de mães pretas $\left(70,9 ; \mathrm{IC}_{95 \%} 58,5\right.$ $85,9)$ ou pardas $\left(71,5 ; I_{1} 95 \% 67,4 ; 75,8\right)$, com idades $\leq 19\left(70,3 ; I_{95 \%} 63,5 ; 77,8\right)$ ou $\geq 40$ anos $\left(62,1 ; I_{95 \%} 46,6 ; 82,6\right), \leq 3$ anos de estudo $\left(73,4 ; I_{95 \%} 58,2 ; 92,4\right)$ e residentes na região Nordeste $\left(138,7 ; I^{\prime} C_{95} \% 130,9 ; 147,0\right)$.

Identificar as necessidades parentais quanto ao cuidado para o desenvolvimento de lactentes e crianças com microcefalia causada pelo vírus da Zika (ZIKV).

Os participantes relataram a necessidade de maior atenção, compreensão e apoio psicossocial por parte da instituição e dos profissionais envolvidos; mais conhecimento sobre o contexto geral da condição da criança; e intervenções educativas em saúde com acompanhamento continuado (follow-up) voltadas para as reais necessidades das crianças e suas famílias.

Fonte: Dados da pesquisa, 2015 a 2017.

REAS/EJCH | Vol.Sup.n.38 | e1705 | DOI: https://doi.org/10.25248/reas.e1705.2020 Página 6 de 9 


\section{Epidemia do Zika vírus e a microcefalia a relação da desigualdade econômica}

Pelo levantamento dos dados, houve um aumento, passando de uma média anual de casos de microcefalia que foi 164 no período 2000-2014, para o ano de 2015 com registros de 1.608 casos, um destaque importante nesse período de epidemia se traçou um perfil epidemiológico, o perfil das mães dos nascidos vivos com microcefalia. Dos 1.608 nascidos vivos com microcefalia em $2015,71 \%$ eram filhos de mães residentes na região Nordeste; $51 \%$, de mães com até 24 anos de idade; $77 \%$, de mãe com cor da pele preta ou parda; e $27 \%$, de mães com menos de oito anos de escolaridade (MARINHO F, et al., 2016).

Esse perfil é indicativo de marcantes desigualdades sócio demográficas e geográficas na ocorrência desse agravo (MARINHO F, et al., 2016).

As características familiares de crianças atingidas pela complicação estão relacionadas à dificuldades socioeconômicas graves, como é o caso das mães de crianças microcefálicas de Sergipe que possuíam renda média de $R \$ 266,00$. Em Pernambuco, a média per capita familiar de crianças com microcefalia foi $R \$ 400,00$, rendas abaixo da média do restante do país, sendo um desafio para o sistema de assistência à saúde, pois através pesquisas ainda busca-se entender o significado do espectro real do potencial teratogênico deste vírus. Esse fato confirma que as famílias de menor poder aquisitivo são mais vulneráveis a contrair o vírus, e torna mais difícil cuidar de seus filhos que precisam de cuidados especiais para vida toda (PEREIRA EL, et al., 2016).

\section{Políticas públicas, olhar humanizado para as famílias}

Em decorrência do impacto expressivo causado na saúde pública pelo Zika vírus, devem ser adotadas políticas públicas de saúde e de inserção social para as crianças e suas famílias, decorrente do aumento de casos de microcefalia no Brasil (SANTOS JLG, et al., 2016).

Santos JLG, et al. (2016) afirma que o poder público deve realizar políticas de conscientização e campanhas educativas para medidas de controle da doença, nos âmbitos âmbito federal, estadual, distrital e municipal. Como também, informar a população sobres as características da patologia, pois muitas vezes a família não saber lidar com a doença preferindo o aborto (PEREIRA S, et al., 2016).

Entretanto, não só a família tem o papel fundamental para o crescimento e desenvolvimento da criança que foi diagnosticado com deficiência, mas a disponibilização de políticas que fortaleçam e ofereçam a inclusão social, educação em saúde, apoio financeiro às pessoas com vulnerabilidade e o reconhecimento dos direitos, ajudam a modificar a realidade ao proporcionar uma melhor qualidade de vida e diminuir os preconceitos vividos pela família na sociedade. Garantir o acesso das crianças com microcefalia associada ao Zika vírus e suas famílias aos equipamentos da proteção social básica é fundamental para promover a inserção social da rede ampliada que poderá auxiliar no cuidado das crianças com microcefalia (PEREIRA ÉL, et al., 2017).

\section{Brasil e o Zika vírus, as grandes descobertas}

Há registro de circulação do vírus Zika em todo Brasil. Em 2015, foram confirmados laboratorialmente três óbitos por Zika, nos municípios de Benevides - PA, São Luís - MA e Serrinha - RN (BRASIL, 2016).

Durante esses anos foi possível através de muitas pesquisas traçar o perfil do vírus para uma vacina junto com outros órgãos estrangeiros e vários centros de pesquisas no Brasil. Até o momento, foi concluída a avaliação da linhagem celular para o crescimento do vírus Zika e estão em desenvolvimento os bancos de células e vírus para apoiar a produção e desenvolver testes de especificação de produto. A estrutura de desenvolvimento de novas vacinas está em fase de contratação do projeto executivo da obra, e os equipamentos previstos no projeto estão em fase de aquisição (BRASIL, 2018).

Outro fator importante são as dificuldades para reconhecimento e manejo clínico, o vírus Zika muitas vezes é confundido com Dengue e Chikungunya. Desde abril de 2015 temos a presença desses três vírus no Brasil, mas ainda há a necessidade de se ampliar a divulgação sobre os sintomas e, principalmente, as diferenças entre os três (FUNDAÇÃO OSWALDO CRUZ, 2015). 
A confiabilidade dos resultados dos testes laboratoriais depende do período e dos cuidados durante a coleta, manuseio, acondicionamento e transporte dos espécimes biológicos, destacando-se a baixa viabilidade do vírus Zika frente ao manuseio, como exemplo congelamento e descongelamento (BRASIL, 2016).

\section{Prevenção}

O foco deve ser colocado nas medidas preventivas de proteção individual. Os viajantes que pretendam deslocar-se para países com transmissão do vírus Zika deverão ser aconselhados a tomar precauções contra o mosquito, que é recomendado o uso de repelente de insetos, seguro de utilizar inclusive na grávida durante 0 aleitamento (BROGUEIRA P e MIRANDA AC, 2017).

Nos locais de alojamento deve utilizar redes mosqueteiras, mesmo durante o dia. As grávidas são desaconselhadas a viajar para áreas de risco de transmissão, no entanto, na impossibilidade de adiar a viagem, devem adaptar as medidas gerais de evicção da picada e, para além disso, abstinência sexual ou uso do preservativo até ao final da gravidez. As grávidas, mesmo assintomáticas, devem ser avaliadas quanto à ocorrência de infecção por vírus Zika e seguir um plano de seguimento obstétrico adequado (BROGUEIRA P e MIRANDA AC, 2017).

\section{Equipe multidisciplinar}

A microcefalia congênita que acomete o bebê, provoca o desenvolvimento de diversas alterações, como deficiência intelectual, limitações físicas, epilepsia, dificuldades físicas e auditivas e distúrbios comportamentais (FÉLIX VPSR E FARIAS AM, 2018).

Através do risco do acometimento das alterações causadas pela microcefalia, a assistência prestada para esses bebês necessita do acompanhamento de uma equipe multidisciplinar, incluindo diversos profissionais da área da saúde como pediatra, fisioterapeuta, fonoaudiólogo, entre outros (HASUE RH, et al., 2017).

Orientar sobre como vai ser a vida da criança para os pais é importante pois irá garantir a interação com outras pessoas do convívio, a partir do momento do diagnostico a equipe deve passar segurança e apoio aos pais que estão fragilizados com o diagnóstico (NOGUEIRA ACS et al., 2019).

\section{$O$ apoio da enfermagem a criança com microcefalia adquirida por Zika vírus}

Os profissionais de enfermagem têm importância para o cuidado dessas crianças com microcefalia. No acompanhamento gestacional, prioritariamente com início no primeiro trimestre da gravidez, é fundamental para a identificação de fatores de risco (NASCIMENTO MSA, et al., 2019).

Ao profissional de enfermagem que irá lidar com a criança desde o momento do nascimento, cabe o papel de avaliação contínua, orientações referentes aos cuidados que deverão ser prestados a criança, apoio emocional aos familiares, identificação precoce de alterações nos sistemas, para seu devido tratamento o mais rapidamente possível, além de prestação de assistência diante dos agravos, o que necessita do profissional, adequado conhecimento para lidar com essas situações especificas (MEDEIROS F, et al., 2018).

A microcefalia não possui tratamento específico. No entanto, existem medidas de suporte que auxiliam o desenvolvimento do bebê e da criança, que é preconizado pelo Sistema Único de Saúde (SUS). O acompanhamento profissional de diversas especialidades vai depender da complicação desenvolvida e das funções que ficarem comprometidas, sendo elas, neurológicas, motoras e respiratórias (SÁ RAMTA, et al., 2017).

\section{CONSIDERAÇÕES FINAIS}

Os dados analisados, permitiu constatar que investir em educação em saúde, incentivo ao pré-natal, diagnóstico, prevenção e saneamento básico são fundamentais para o controle do vetor, sendo a atuação do enfermeiro (a) nos três níveis de atenção (primária, secundária e terciária) essencial, para que no futuro as gerações não sofram com o vírus e suas consequências. A partir do estudo foi possível perceber a escassez 
de dados que aborde o assunto, sendo necessário investimentos em pesquisas sobre o Zika vírus, visto sua semelhança com outras doenças, o que é considerado uma limitação neste estudo. Logo, o trabalho proposto buscou contribuir para alarmar sobre o reduzido número de protocolos voltados a atuação do enfermeiro e descoberta imediata do vírus, além de contribuir com a temática para futuras pesquisas.

\section{REFERÊNCIAS}

1. BRASIL. Ministério da Saúde. Secretaria de Vigilância em Saúde. Monitoramento dos casos de dengue, febre de Chikungunya e febre pelo vírus Zika até a Semana Epidemiológica 16, 2016. Boletim Epidemiológico, v. 47 № 20 2016.

2. BRASIL. Divulga primeiro balanço com casos de Zika no País, 2016.

3. BRASIL. Ministério da Saúde. Zika, 2019.

4. BRASIL. Plano de cooperação em saúde para o enfrentamento do vírus zika - monitoramento e resultados, 2018.

5. BROGUEIRA P, MIRANDA AC. Vírus Zika: Emergência de um Velho Conhecido. Medicina Interna vol.24 no.2 Lisboa jun. 2017.

6. CASTRO R. Estudo confirma relação entre a infecção pelo vírus da Zika e microcefalia. Fiocruz, Pernambuco,20 de setembro de 2016.

7. EICKMANN SH, CARVALHO MDCG, RAMOS RCF, et al. Síndrome da infecção congênita pelo vírus Zika. Cad. Saúde Pública, Rio de Janeiro, jul, 2016.

8. FÉLIX VPSR E FARIAS AM. Microcefalia e dinâmica familiar: a percepção do pai frente à deficiência do filho. Cad. Saúde Pública 2018; 34(12):e00220316.

9. FUNDAÇÃO OSWALDO CRUZ. Zika, Chikungunya e Dengue: entenda as diferenças. Agência Fiocruz de notícias, 2015.

10. HASUE RH, et al. A síndrome congênita do vírus Zika: importância da abordagem multiprofissional. Fisioter. Pesqui. vol.24 no.1 São Paulo Jan./Mar. 2017. http://dx.doi.org/10.1590/1809-2950/00000024012017.

11. MARINHO F, et al. Microcephaly in Brazil: prevalence and characterization of cases from the information system on live births (Sinasc), 2000-2015. Epidemiologia e Serviços de Saúde:Revista do Sistema único de Saúde do Brasil, v. 25, n. 4, p. 701-712, 2016.

12. MEDEIROS VAB, et al. Assistência de enfermagem ao neonato com microcefalia. Ciências Biológicas e de Saúde Unit | Alagoas | v. 4 | n. 2 | p. 67-76 | Maio. 2018 | periodicos.set.edu.br.

13. NASCIMENTO MSA, et al. Assistência em saúde prestada à criança com diagnóstico de microcefalia, em um município do interior da Amazônia. 2019; ISSN: 1809-9475 | e-ISSN: 1982-1816.

14. NOGUEIRA ACS, et al. Assistência de enfermagem ao neonato com microcefalia. Revista Científica Multidisciplinar Núcleo do Conhecimento. Ano 04, Ed. 05, Vol. 02, pp. 98-113 Maio de 2019. ISSN: 2448-0959.

15. PEREIRA ÉL, et al. Perfil da demanda e dos Benefícios de Prestação Continuada (BPC) concedidos a crianças com diagnóstico de microcefalia no Brasil. Ciência \& Saúde Coletiva, 22(11):3557-3566, 2017.

16. PEREIRA S, et al. Vírus Zika e gravidez. Acta Obstet Ginecol Port vol.10 no.2 Coimbra jun. 2016.

17. REIS RP. Aumento dos casos de microcefalia no Brasil. Revista Medicina de Minas Gerais, v.25, p. 88-91, 2015.

18. SÁ RAMTA, et al. Infecção do vírus Zika em gestantes e microcefalia. Rev. Bras. Ginecol. Obstet. vol.39, no.5, Rio de Janeiro, Maio, 2017.

19. SALGE AKM, et al. Infecção pelo vírus Zika na gestação e microcefalia em recém-nascidos: revisão integrativa de literatura. Rev. Eletr. Enf. [Internet], 2016.

20. SANTOS JLG, et al. Zika virus and measures of legal interventions in public health. J Hum Growth Dev.; 26(3): 393397. 2016.

21. VASCONCELOS, PFC. Doença pelo vírus Zika: um novo problema emergente nas Américas? Rev Pan-Amaz Saude, Ananindeua, 2015. 